\title{
Optimal forecasting of thermal conductivity and storage in parabolic trough collector using phase change materials
}

\author{
P. Muruganantham* and Balaji Dhanapal** \\ *Associate Professor Department of Mechanical Engineering, \\ Saintgits College of Engineering Kottukulam Hills, \\ Pathamuttom, Kottayam, Kerala \\ **Professor, Department of Mechanical Engineering, \\ Hindustan Institute of Technology \& Science, Padur, Kelambakam, \\ Chennai, Tamil Nadu \\ *Corresponding Author: ppmtech3002@gmail.com
}

Submitted: $08 / 11 / 2018$

Revised: $\quad 23 / 10 / 2020$

Accepted: $01 / 11 / 2020$

\begin{abstract}
Renewable energy is one of the cleaner energy generation strategies practiced all over the world to reduce environmental impacts and waste based on current sustainability in economic practices. Solar energy is one kind of renewable sources of energy practiced for different application. The thermal storage system in solar energy is one of the least practiced methods in research, and the utilization of solar energy in the thermal application is attaining higher responses and is quite possible. In this paper, solar heat generation is attained by solar parabolic trough collector using phase change materials. The ideology behind this research is to develop a thermal energy storage system using solar collectors and phase change materials. A composition mixture of $\mathrm{MgCl}_{2} .6 \mathrm{H}_{2} \mathrm{O}$ phase change materials used as the fluid medium in trough collector and thermal efficiency of the material is evaluated. For effective optimization, an imperialist competitive algorithm is used for optimizing the thermal efficiency of the solar collectors. The thermal efficiency of the collector is numerically experimented in the running platform of Mat Lab and executed in terms of heat gain, heat loss, and thermal efficiency of the parabolic trough collector, respectively. The efficiency of the proposed framework is $85 \%$, and the current framework just has $80 \%$ efficiency. The heat loss in the proposed framework is lower than that of the current system, distinguished as $4200 \mathrm{~W}$ and $4520 \mathrm{~W}$, respectively. It is shown from the research study that the proposed PCM composition is an optimal method for generating heat energy in solar parabolic trough collectors.
\end{abstract}

Keywords: Renewable Energy; Solar Energy; Phase Change Materials (PCM); Mat Lab; Imperialist Competitive Algorithm (ICA); Parabolic Trough Collector. 


\begin{tabular}{|c|c|c|c|}
\hline \multicolumn{4}{|c|}{ Nomenclature } \\
\hline$Q_{u}$ & Useful energy & $T_{f}^{n}$ & The actual temperature of the collector $\left({ }^{0} \mathrm{C}\right)$ \\
\hline$K_{\text {cam }}$ & The angle of the incidence correction factor & $p$ & Probability \\
\hline$q u$ & Power gained to the collector & $\mathrm{B}, \mathrm{Q}$ & vectors \\
\hline$A_{A, \text { int }}$ & $\begin{array}{l}\text { Area of the internal surface of the absorber } \\
\text { tube }\left(\mathrm{m}^{2}\right)\end{array}$ & & Greeks \\
\hline$T_{F}$ & Temperature of fluid $\left({ }^{\circ} \mathrm{C}\right)$ & $\rho_{m}$ & reflectance factor of the mirror \\
\hline$h_{F}$ & Coefficient of a heat exchanger & $\alpha$ & the absorption coefficient of the absorber tubes \\
\hline $\mathrm{Nu}$ & Nusselt number & $\gamma$ & intercept factor \\
\hline$K_{F}$ & Thermal conductivity of the fluid (W/mk) & $\eta$ & Thermal efficiency \\
\hline$f$ & Coefficient of friction & & Abbreviations \\
\hline$Q_{v}$ & The volume of flow rate $\left(\mathrm{m}^{3}\right)$ & PCM & Phase Change Materials \\
\hline $\operatorname{Pr}$ & Prandtl number & ICA & Imperialist Competitive Algorithm \\
\hline$h_{r}$ & Radiation heat transfer coefficient & PV & Photovoltaic \\
\hline$q L$ & Total heat loss & TES & Thermal Energy Storage \\
\hline$n$ & Number of receivers in the collector module & CSP & Concentrated Solar Thermal power \\
\hline$I$ & Direct normal solar radiation & $\mathrm{HEF}$ & Heat Exchange fluid \\
\hline$A_{c}$ & Aperture area of the collector & LTES & Latent Thermal Energy Storage \\
\hline$C_{p}$ & Constant pressure specific heat & & \\
\hline$m$ & The mass flow rate of fluid & & \\
\hline$\left(T_{\text {out }}\right)$ & Outlet temperature $\left({ }^{\circ} \mathrm{C}\right)$ & & \\
\hline$\left(T_{i n}\right)$ & Inlet temperature $\left({ }^{\circ} \mathrm{C}\right)$ & & \\
\hline
\end{tabular}

\section{INTRODUCTION}

In the current circumstances, renewable power sources have picked up a remarkable significance because of their overall social recognition and a capacity to give sustainable energy generation to provide world energy requirements. Energy is required for all segments appropriate from consistent need, buildings, and entertainment. The accessibility of conventional energy sources like oil, petroleum gas, and coal is draining at a disturbing rate around the world. Solarthermal energy storage systems are considered to be the two major subsystems in solar thermal applications. A solar collector, the remarkable energy exchanger, turns over solar oriented illumination energy to either the thermal energy of the working liquid in solar oriented thermal applications or the electric energy particularly in photovoltaic (PV) applications (Richareon et al., 2016). Solar photovoltaic (PV) power generation and concentrated solar thermal power (CSP) are the two principle advances for solar energy generation. A CSP framework may utilize a solar based power tower, parabolic troughs, or linear Fresnel reflectors to concentrate light and deliver extreme heat, which is diverted by a heat exchange fluid (HTF) to send to the thermal power plant for power generation (Liu et al., 2016). Among all the solar based heat power generation approaches, the parabolic trough sun oriented warm power generation frameworks have pulled in incredible considerations and accomplished business applications. A CSP with thermal energy storage (TES) framework turns into the principal decided to give adaptability to chain power supply and service at an expansive scale on account of the vast limit of thermal storage for power generation (Bijarniya et al., 2016).

Since the stage progress enthalpy of phase change materials (PCMs) is significantly higher than sensible heat, latent heat storage has substantially higher capacity thickness than sensible heat storage (Mao et al., 2016). The primary property of PCM material is to store and ingest/discharge heat that covered latent thermal near a steady 
temperature during its melting, cooling, and hardening progress stages (Cunha et al., 2016; Zhang et al., 2016). This is an extremely one of a kind property in energy generation processes, where a high temperature or thermal source is required inside a limited or low confined temperature run as the thermal contribution to the energy. These materials can store energy by melting at a consistent temperature. There is no immaculate PCM material without disadvantages, so the choice of a PCM for a given application requires extremely cautious attention including its mixes, having a low melting point. PCMs are widely used as a part of latent thermal energy storage (LTES) system and thermal management (TM) system because of their vast constant temperature and capacities of keeping up the almost steady temperature.

Thermal energy system (TES) can be executed as sensible heat utilizing solid or fluid medium, latent heat utilizing PCM, and chemical energy utilizing a reversible reaction of chemicals. Usage of TES depends on latent heat storage utilizing PCM (Almsater et al., 2016). Since the expansive amount of heat can be provided or separated from PCM without a critical difference in the temperature, PCMs can be likewise connected to control and balance out temperature in a thermal management (TM) system (Liu et al., 2016). The energy management system is subsequently continuously being presented in many organizations, together with data frameworks helping in information-gathering operations, respectively ( $\mathrm{Li}$ et al., 2016). Parabolic trough collector equipment can determine power production frameworks with working temperatures. These are identified as the most significant sun based warm control advancements for producing current or warmth. The approaching sunlight based radiation that arrives at the illustrative trough mirror is concentrated on the gatherer cylinder surface. The procedure includes the blend of radiative, convective, and conductive energy moved with the liquid stream.

The purpose of this research is to identify the thermal storage in the parabolic trough collector using phase change materials. This research paper is organized as follows. The past literature survey on the research is elaborated in section 2; section 3 describes the proposed methodology about the current research being carried out, and the experimentation and result discussion are elaborated in section 4 . The final section is the research conclusion.

\section{LITERATURE SURVEY}

Renewable energy resources and significant opportunities for energy efficiency over wide land areas, rather than other energy sources, are gathered in a set quantity of nations. Energy efficiency, and mechanical improvement of energy sources, would bring about critical energy security and financial advantages. The world has seen a dynamic move of the energy scene as far as utilization, which has been radically expanded and has dependence on energy resources. Some of the previous studies related to the present investigation are discussed in the following sections.

Qui et al. 2017 established a coordinated numerical model to solve the complex energy move in a parabolic trough collector by joining Monte Carlo beam following and finite volume technique. The warm performance of PTC by utilizing supercritical $\mathrm{CO}_{2}$ as warmth exchanger fluid was studied. Outcomes indicated that the sunlight fluxes on the receiver walls were nonuniform. The circumferential heat difference of absorber was established to diminish with expanding or decreasing inlet velocity.

Chandra et al.(2017) described the air-filled receiver frameworks and attempted an extension of economy and proficiency between the two sorts of frameworks utilizing computational fluid dynamics based numerical recreation approach. Convective warm losses were explored for changing mass stream rates of heat transfer fluid. The outcomes demonstrated that the parabolic trough collectors were reasonable for the small scale process warm applications in India.

Bellos et al.(2019) examined the utilization of various nanoparticles dispersed in thermal oil as nanofluids in parabolic trough collector. Effects of solar irradiation level on the thermal efficiency enhancement were explored. The last outcomes indicated that the most proficient nanoparticles were the $\mathrm{Cu}, \mathrm{CuO}, \mathrm{FE}_{2} \mathrm{O}_{3}, \mathrm{TiO}_{2}, \mathrm{Al}_{2} \mathrm{O}_{3}$, and $\mathrm{SiO}_{2}$. It was discovered that the improvements were monitored for low stream rates, higher temperature, and larger nanoparticle focuses. 
Heng et al.(2019) presented a fast and accurate transient thermal prediction method to predict the parabolic trough collector tube exit temperature. The artificial neural network is combined with the principles of superposition. Conjugate heat transfer analytical results were obtained by the finite element method utilized to train the ANN. The optimum performance of the collector tube under multiple radiation conditions was assessed during the early design phase of parabolic trough system. The predicted results were utilized for initial system planning, heat balance analysis, and system design. The method provided good prediction capability under the fluctuating solar radiation, as well as stable solar radiation.

Arunkumar et al.(2017) presented a compound parabolic concentrator (CPC) concentric circular tubular solar still (CCTSS) with phase change material (PCM). Experimentations were carried out with and without phase change material in CCTSS. The PCM is loaded in the specially designed circular trough of tubular solar still. The temperatures of water, air, and outer cover were measured on infrequent intervals. The results indicated that the freshwater production of CPC-CCTSS with phase change material produced enhanced results.

Kargar et al.(2018) presented a numerical analysis of thermal energy storage (TES) system using phase change material for direct steam solar power plants. Integrated system performance constitutes the concepts of thermal storage system, which was analyzed numerically. The effects of thermal conductivity of PCM. Heat transfer fluid flow rate and the diameter of heat exchanger tubes were analyzed during the entire thermal cycling of the evaporator. The results indicated that the thermal conductivity of PCM was the most effective parameter, and an increase in the parameter decreases the charging time and increases the output steam quality during the discharging process. It was identified that the cascade arrangement in the preheater and superheater warmth exchangers results in lower temperature gradient of the output HTF.

Menbari et al.(2017) implemented a design to investigate the absorption and thermal conductivity of binary nanofluids and to evaluate the factors involved in the optimal stability. Two dissimilar nanoparticles, $\mathrm{CuO}$ and $\gamma$-A12O3, with high properties of absorption and scattering, respectively, were chosen to prepare a nanofluid, and the results showed that the thermal conductivity and aggregation of the prepared nanofluid were highest and lowest under optimal stability. The effects of binary nanofluid on the thermal efficiency of direct absorption solar parabolic trough collector (DASPTC) were evaluated. The DASPTC collector revealed that the thermal efficiency of the system could be enhanced by increasing nanoparticles volume fraction and flow rate of nanofluid.

In solar collector applications, water and certain synthetic oil are normally used as a conventional fluid for power generation purposes. However, the heat exchanging capacity and the thermal efficiency rates are minimal when using such fluids. As a new trend, the contribution of nanofluids is more favoured for exchanging heat. This is because of its better thermal conductivity characteristics. Several types of research have been focused on increasing the heat exchanging behaviour. Wang et al.(2016) utilized the $\mathrm{Al}_{2} \mathrm{O}_{3}$ /synthetic oil nanofluid for enhancing the thermal performance of parabolic trough solar collector. Besides, the thermal efficiency rates are maximum when using nanofluids rather than the conventional fluids in the solar collector. The graphite and nanoparticles suspended ethylene glycol fluid is used in solar collectors to enhance its thermal performances (Sani et al., 2018). At the same time, the cost of the nanoparticles is $\$ 750 / \mathrm{kg}$ to $\$ 1000 / \mathrm{kg}$. Nowadays, solar collectors made of phase change materials play a major role in enhancing the efficiency of solar collectors. The thermal efficiency obtained from the PCM based PTC is optimal than the nanofluids. The efficiency of PTC is enhanced upto $85 \%$; at the same time, the $\mathrm{Al}_{2} \mathrm{O}_{3}$ and $\mathrm{SiO}_{2}$ added fluid provided thermal efficiency as $72.53 \%$ and $74 \%$, respectively (Bellos et al., 2019; Norouzi et al., 2020).

\section{PROPOSED RESEARCH WORK}

Solar energy is one of the obtainable renewable energy sources and is supported to be utilized as a part of every nation for its sustainability. Solar radiation is a period subordinate energy source with an irregular character. Thermal energy storage is a fundamental portion of the expanded solar-based heating and cooling systems. The solar energy increases through the normal part of the building envelope, which can decrease energy utilization for heating during 
the summer season along these lines saving the energy from conventional heat sources. The PCMs can be coordinated in constructions to give heat capacity limit and, therefore, to expand the thermal comfort of residents in the buildings with light-weight envelope. The utilization of the stage change materials for inert heat storage has delayed behind that of sensible heat storage. This is incomplete because of the latent heat storage system addressed to an elevated level of innovation.

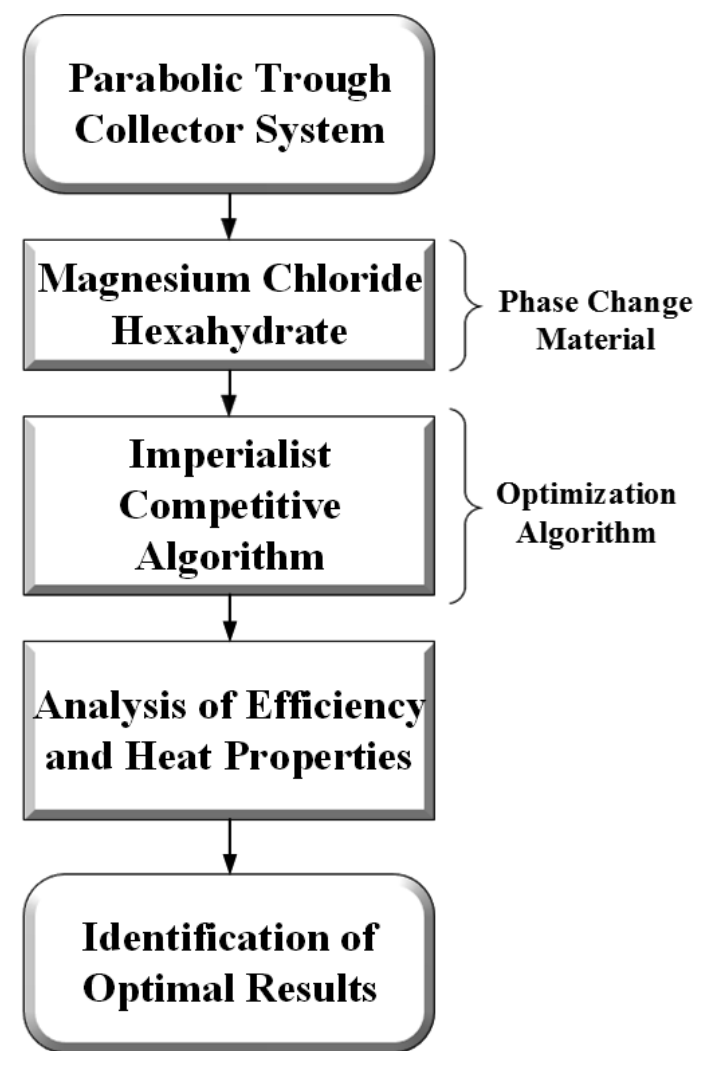

Figure 1. Proposed Architecture of the System.

The architecture of the proposed research work is shown in figure 1, in which the parabolic trough collectors and phase change materials are utilized. In this research paper, the energy storage is undergone by phase change materials in the solar collector, and its performance is evaluated. The solar heat is utilized as the primary source of heat energy generation; the solar parabolic trough is one of the thermal collectors vastly utilized in industries. The primary objective of this research is to evaluate the thermal storage in the parabolic trough collector using phase change materials. A composition of $\mathrm{MgCl}_{2} \cdot 6 \mathrm{H}_{2} \mathrm{O}$ is used as a phase change material in parabolic trough collector. The main contribution of the present research work is to provide a higher proficiency in heat production and storage in solar parabolic trough collectors using PCM. For efficient optimization, an imperialist competitive algorithm (ICA) is used to find out optimal thermal efficiency in thermal collectors. Thus, the combination of PCM based parabolic trough collector conducts more heat energy than conventional trough collector regarding energy storage and generation, which is optimal for use in the renewable thermal energy generation process. The research work is carried out in various places and geometrical areas of India. The efficiency of the PCM collector is numerically modelled and experimented in the running platform of Mat Lab, and the obtained results are highlighted as performance graphs. From the research conclusion, the proposed PCM composition has a higher efficiency of heat generation and storage in solar parabolic trough collectors. 


\subsection{Material Selection}

Solar collectors are utilized to gather and focus the beams to warm up a working liquid to the temperature. This section manages the determination and planning of the experimental setup. Solar trough collectors and phase change materials are considered for the experimentation and discussed below.

Parabolic Trough Collector: Solar collectors are fundamentally used to absorb solar-based energy in the form of heat through a warmth exchange medium and changes over it into the valuable energy (Bellos et al., 2016). The parabolic trough collector is a kind of concentrating solar collector that utilizes the reflected surface of a linear parabolic concentrator to focus direct solar radiation onto an absorber tube running along the line joining the foci of the parabolas. Parabolic troughs concentrate sunlight onto a collector tube that is situated along the focal line of the trough (Ghasemi et al., 2017).

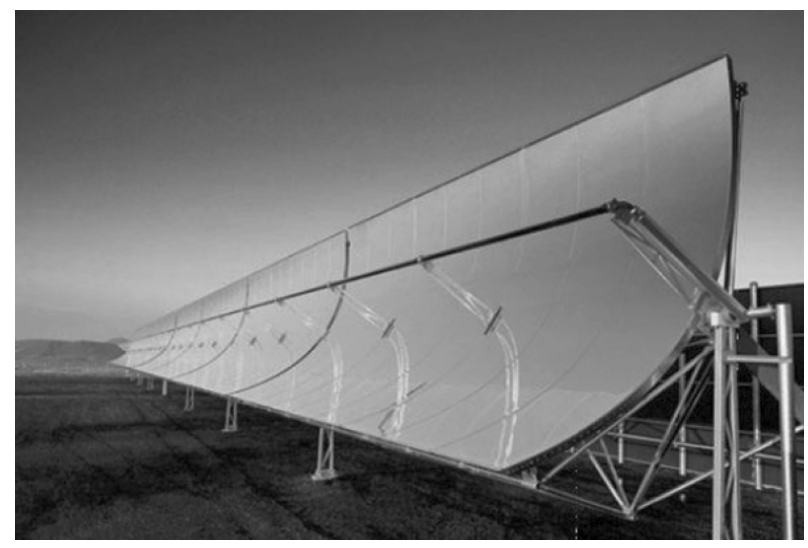

Figure 2. Parabolic Trough Collectors.

The image of parabolic trough collectors generally utilized for the accumulation of energy from the sun is shown in figure 2. The solar energy is harnessed and converted to different forms of energy as per need. In this framework, the solar energy is converted to electrical energy, mechanical energy, and different energy applications like cooking, etc.

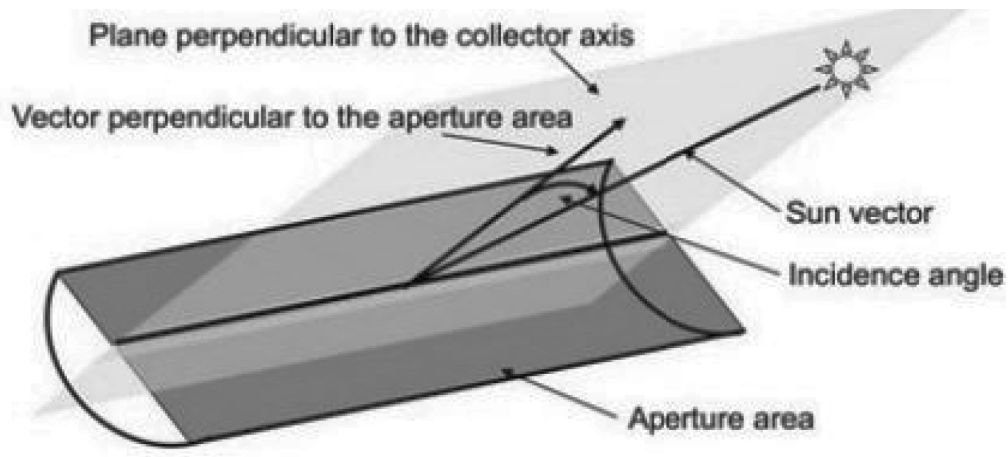

Figure 3. Parabolic Trough Collector in Detail.

The representation of parabolic trough collectors and its operations is shown in figure 3 . The beams from the sun are considered as a vector and occurrence on the trough gatherer. The vector perpendicular to the aperture area and plane perpendicular to the collector axis forms the incident angle.

Phase Change Materials: An efficient phase change material will have a high heat of combination, high warm conductivity, high specific heat, density, and long-term reliability during repeated cycling. Higher warm energy storage 
limit contrasted with the reasonable energy storage in water (Kapsalis et al., 2016). This prompts smaller required storages, and the main advantage is small useful temperature contrasts, which can be accomplished. While phase change materials are abundant in general, since all materials are phased change materials, certain perfect attributes can be recognized for the successful utilization of PCMs. In this experimentation, a composition of $\mathrm{MgCl}_{2} .6 \mathrm{H}_{2} \mathrm{O}$ is used as phase change material in parabolic trough collectors (Deng et al., 2016).

Table 1. Various Properties of Phase Change Materials.

\begin{tabular}{|c|c|c|c|}
\hline Thermal Properties & Chemical Properties & Physical Properties & Economic Properties \\
\hline \multirow{2}{*}{$\begin{array}{c}\text { Phase change temperature fitted } \\
\text { to the application }\end{array}$} & Stability & \multirow{2}{*}{ Low-density variation } & \\
\cline { 2 - 2 } $\begin{array}{c}\text { High change of enthalpy near } \\
\text { the temperature of use. }\end{array}$ & Nonflammable & High density & \multirow{2}{*}{ Cheap and abundant } \\
\hline \multirow{2}{*}{$\begin{array}{c}\text { High thermal conductivity in } \\
\text { both solid and liquid phases }\end{array}$} & $\begin{array}{c}\text { Nonpolluting, } \\
\text { Nontoxic }\end{array}$ & $\begin{array}{c}\text { Compatibility with } \\
\text { container materials }\end{array}$ & \\
\cline { 2 - 2 } & Small or no subcooling & \\
\hline
\end{tabular}

Various properties of phase change materials used in different applications are indicated in table 1. The phase change materials have some advantages like being nonpolluting, nontoxic, highly stable, and cheap in availability. The high-density and low-density variations in the phase change materials help perform more effectively in different conditions (Wang et al.,2016).

Composition of $\mathrm{MgCl}_{2} \cdot 6 \mathrm{H}_{2} \mathrm{O}$ : These combinations are, otherwise, called magnesium chloride hexahydrate. Magnesium chloride hexahydrate is utilized as a catalyst for organic synthesis. This is available as a white crystal at room temperature and a promising heat/thermal storage material, mainly utilized in thermal energy storage due to its high volumetric energy density, relatively high thermal conductivity, low cost, non corrosive, and nontoxic (Ling et al.,2017). The above benefits of magnesium chloride hexahydrate are considered for utilization in this experimentation.

Table 2. Various Properties of $\mathrm{MgCl}_{2} .6 \mathrm{H}_{2} \mathrm{O}$.

\begin{tabular}{|c|c|}
\hline Melting Point & $117^{\circ} \mathrm{C}$ \\
\hline Boiling point & $1412^{\circ} \mathrm{C}$ \\
\hline Density & $1.569 \mathrm{~g} / \mathrm{cm}^{3}$ \\
\hline Solubility & $\mathrm{H}_{2} \mathrm{O}: 1 \mathrm{M}$ at $20^{\circ} \mathrm{C}$ \\
\hline Specific Gravity & 1.569 \\
\hline $\mathrm{PH}$ & $4.5-7.0$ \\
\hline Sensitive & Hygroscopic \\
\hline Stability & Stable \\
\hline Form & Solid, colorless \\
\hline
\end{tabular}

Properties of magnesium chloride hexahydrate materials used in this experimentation are indicated in table 2. These are stable, colorless materials having melting point and boiling point $117^{\circ} \mathrm{C}$ and $1412^{\circ} \mathrm{C}$, respectively. The $\mathrm{PH}$ values of the materials range from 4.5 to 7.0, and the magnesium chloride hexahydrate materials are hygroscopic in nature (Mamani et al., 2018). 


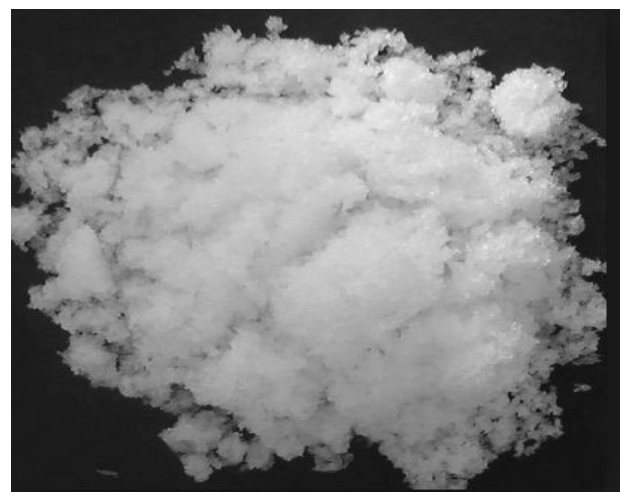

Figure 4. Powdered form of $\mathrm{MgCl}_{2} \cdot 6 \mathrm{H}_{2} \mathrm{O}$.

In figure 4, it represents the powdered form of magnesium chloride hexahydrate materials. These materials have solid structures in normal temperature and can be changed to various states. It is used as the fluid medium in the parabolic trough collector system.

\subsection{Experimental Designing of Parabolic Trough Collector}

The parabolic trough collector system consists of a cylindrical surface of mirrors with a parabolic shape that concentrates the solar radiation into the receiver tube located at the focal point of the parabola. The parabolic trough collector has the configuration of aperture $1.22 \mathrm{~m}$, focal length $20 \mathrm{~m}$, depth of parabola $0.21 \mathrm{~m}$, and arc length $1.83 \mathrm{~m}$, and it is made of stainless steel with mirror film. A fluid circulates inside the receiver tubes, which is heated up by the Sun and pumped through heat exchangers to generate steam, which is then used to produce electricity. The absorber tube is made of copper with a dimension of $0.0254 \mathrm{~m}$ and a length of $1.22 \mathrm{~m}$, respectively. The collectors are fixed to the ground by utilizing the metallic structure and concrete. Parabolic trough reflectors are the concentrating part of the collector. It reflects solar radiation and transfers it to the receiver tube. The phase change materials are used in the parabolic trough collectors (Widyolar et al., 2018). A combination of $\mathrm{MgCl}_{2} \cdot 6 \mathrm{H}_{2} \mathrm{O}$ is used as the phase change material. The combination of phase change materials and parabolic trough collectors conducts more heat than the normal trough collectors in terms of the energy generation and storage. The phase change materials are used as the fluid medium in trough collectors. The fluid storage tank has the capacity of 10 and 28 liters, with oil circulation pump of $0.5 \mathrm{~kW}$ capacity being used. The main aim behind the experimentation is to develop a thermal energy storage system by utilizing the solar collectors and phase change materials. The $\mathrm{MgCl}_{2} \cdot 6 \mathrm{H}_{2} \mathrm{O}$ phase change materials used as the fluid medium in trough collector and thermal efficiency of the material are evaluated.

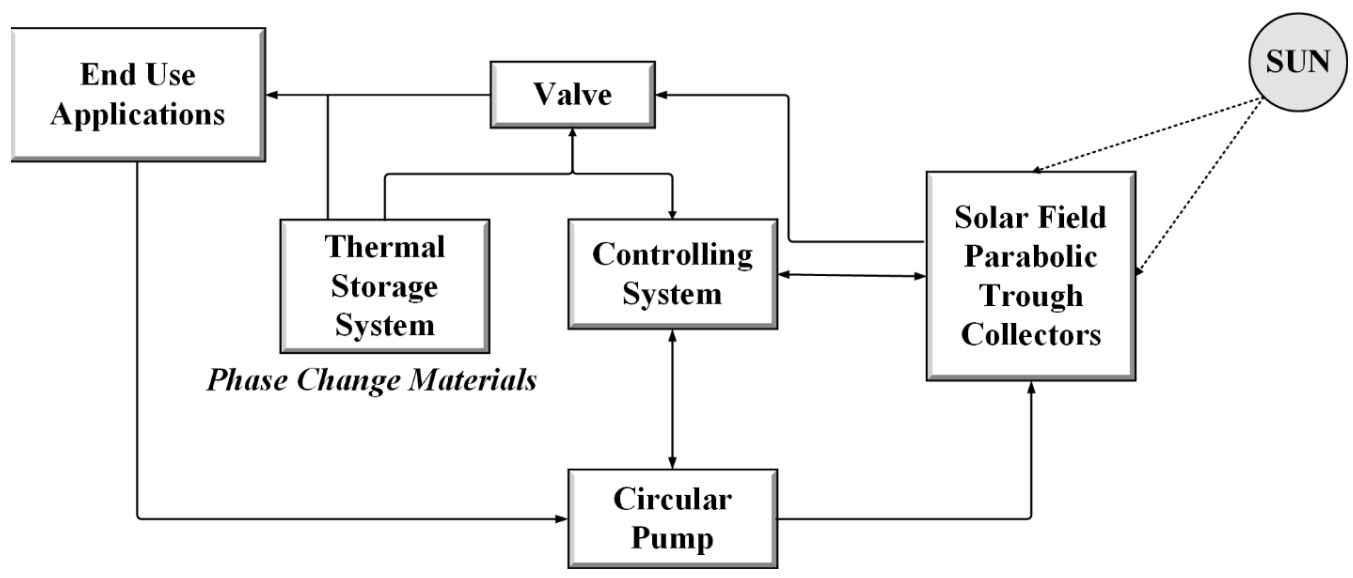

Figure 5. Arrangement of Parabolic Solar Trough Collector System. 
Figure 5 shows the arrangement of a parabolic trough collector system used in the experimentation. The parabolic trough collectors are used to collects the solar energy, and the thermal energy is stored in the thermal energy storage system. The circular pump is used to circulate the heat transfer materials. These are controlled by the controlling system in the parabolic trough collector system. The circulation subsystem carries fluid and transfers the heat received by it to the end-use application. The thermal storage subsystem is part of the circulation system. It sends signals to these systems when the temperature becomes too high. When the temperature is too low, it supplies stored heat to the fluid. The temperature values of fluids and thermal storage system are analyzed, and the input data are given to the proposed imperialist competitive algorithms. The trough collector efficiencies are identified by using the equations that are discussed in the following sections. The Mat Lab working platform is used for the simulation of results of thermal efficiency and heat loss of the parabolic trough collector system.

The issue that arose in the optimization of thermal effectiveness of the solar parabolic trough collector framework is the boosting of Nusselt number with minimization of weight drop. Requirements of the issues are Reynolds number and Richardson number, as well as the side constraints of the design variables. These are solved by utilizing imperialist competitive algorithms.

\section{i. Imperialist Competitive Algorithm}

It is a recently developed metaheuristic algorithm for the optimization of collector performance, thereby analyzing the competition of collectors. The algorithm is initiated with the randomly generated population of size $N$, and it is denoted as solar collectors. The ICA validates the cost function of collector, which will be a specific problem in optimization. The parabolic trough collector is initially divided into imperialist and colonies. The imperialist reaches better collector's performance in the population, and colony is the remaining collector's leftover. The divided colonies are distributed randomly to the imperialist. The colonies obtained by the imperialist are proportional to their power decrement. The efficiency function induced in the ICA validates the collector's performance based on the efficiency of the collector. The empire formulated in the ICA describes the imperialist with its colonies; thus, several imperialists and their empire are initialized in the optimization process. After the initialization of the empire, the position of colonies is arranged according to the imperialist, which is known as assimilation process. In the meantime, some of the colonies are selected randomly and replaced with updated collectors, and this is known as revolution process. In case the colony is better than imperialist during the explained processes, the colony and imperialist shift their roles for better outputs (Al Dossary et al., 2016). The optimization of collector's performance is evaluated by the ICA using dimensional optimization $N_{\text {var }}$, which is highlighted as $1 \times N_{\text {var }}$. The array function is defined by the following equation:

$$
\text { Firms }=\left(x_{1}, x_{2}, x_{3}, \ldots x_{N_{\text {var }}}\right)
$$

Where $x_{i} S$ are the variables to be optimized. The evaluation of parameters for thermal collector's performance is represented as variables. The variables in the collector determined are time and temperature. These are the constraints utilized for the optimization of the collector performance.

The performance of the collector during heat generation is evaluated from the variables $\left(x_{1}, x_{2}, x_{3}, \ldots . x_{N_{\text {var }}}\right)$ as

$$
\text { Time }=f(\text { collectors })=f\left(x_{1}, x_{2}, x_{3}, \ldots . x_{N_{\text {var }}}\right)
$$

For the optimization process, the population size is developed and termed as $N_{\text {collector }}$. Thus, by selecting $N_{\text {imp }}$ important collectors to form empires, the remaining portion of $N_{c o l}$ of the colonies belongs to each empire.

For the implementation of empires, the colonies are divided into collectors based on the collector's performance, which is specified as the initial ratio of colonies that is directly proportional to the collector's performance. The time function of the collector is evaluated to classify the colonies fraction through the collectors. The actual time induced in the thermal collector is evaluated from by following equation [3]: 
$T_{f}^{n}=t_{f a}^{n}-\max \left\{t_{i}^{n}\right\}$

where $t_{f a}^{n}$ is the $n^{\text {th }}$ number of cost in the collector, and $T_{f}^{n}$ is the actual temperature of the collectors evaluated. After the verification of actual temperature, the performance validation of each collector is defined by

$$
P_{f}^{n}=\left|\frac{T_{f}^{n}}{\sum_{i=1}^{N_{\text {imp }}} T_{i}^{n}}\right|
$$

The colonies are divided based on the collector's performance. Therefore, the initial colonies for $n^{\text {th }}$ of collector are

$$
N . T_{f}^{n}=\operatorname{round}\left\{P_{f}^{n} . N_{c o l}\right\}
$$

The initial colonies in $n^{\text {th }}$ of the number of collector's are denoted as $N \cdot T_{f}^{n} N_{c o l}$ is the initial number of colonies chosen initially. For dividing the colonies, the initial colonies are randomly chosen and fed to $n^{\text {th }}$. The optimization of colonies is done by the imperialist, where the colonies migrate to the imperialist at $y$ units, and it is chosen randomly with uniform distribution. The update of imperialist is derived from the following equation:

$$
y \approx U(0, \beta \times d)
$$

where ' $\omega$ ' is the chosen random number, which is greater than $1, ' D$ ' is the distance from colony to imperialist, and $\beta>1$ defines the better colonies that reached the imperialist state from any direction.

\section{ii. Total Performance of an Empire}

The performance of empire might affect the performance of imperialist colonies. But the performance in colonies is approximately equal to the performance of the empire. The performance of the thermal collectors can be modelled by the total temperature time. The total temperature time of the thermal collectors for heating is defined by

$$
T \cdot T_{f}^{n}=\text { Time }_{\left(\text {imperialist }_{n}\right)+\xi} \text { mean }\left\{\text { Time }\left(\text { colonies of empire }{ }_{n}\right)\right\}
$$

here $T . T_{f}^{n}$ is the total time of temperature evaluated in the $n^{\text {th }}$ empire, and $\xi$ is a positive number, which is considered to be low for validating the time of the empire that will be less than 1 .

\section{iii. Imperialistic Competition}

For the thermal collector's competition, the probability of possession of each empire is evaluated based on its total performance. The actual performance of the collectors is retrieved by

$$
N . T . T_{f}^{n}=T . T_{f}^{n}-\max \left\{T . T_{i}^{n}\right\}
$$

where T.T $T_{f}^{n}$ and N.T.T $T_{f}^{n}$ are the total and normalized performance of $n^{\text {th }}$ several empires. From the performance of the empire, the possession probability of the empire is evaluated by the following equation [9]:

$$
P_{p_{f}^{n}}=\left|\frac{N \cdot T \cdot T_{f}^{n}}{\sum_{i=1}^{N_{\text {inp }}} N \cdot T \cdot T_{i}^{n}}\right|
$$

The colonies are divided in terms of empires based on the probability, and the division process is taken into vector form as $Q$. 
$Q=\left[Q_{x_{1}}, Q_{x_{2}}, Q_{x_{3}}, \ldots ., Q_{X_{N_{\text {inp }}}}\right]$

Thus, by defining the vector with the same size as " $x$ ", whose elements are uniformly distributed random number as $V$.

$$
\begin{aligned}
& V=\left[v_{1}, v_{2}, v_{3}, \ldots, v_{N_{\text {inp }}}\right] \\
& v_{1}, v_{2}, v_{3}, \ldots ., v_{N_{\text {inp }}} \approx U(0,1)
\end{aligned}
$$

Vector $B$ is calculated by simply subtracting $V$ from $Q$

$$
\begin{aligned}
& B=V-Q=\left[B_{1}, B_{2}, B_{3}, \ldots \ldots, B_{N_{\text {inp }}}\right] \\
& B=\left[Q_{x_{1}}-v_{1}, Q_{x_{2}}-v_{2}, Q_{x_{3}}-v_{3}, \ldots . ., Q_{x_{N_{\text {inn }}}}-v_{N_{\text {inp }}}\right]
\end{aligned}
$$

From the result, vector $B$ defines the colonies of an empire with index ' $B$ ' being the maximum (Aghajani et al., 2016).

\section{EXPERIMENTAL ANALYSIS AND RESULT DISCUSSION}

The proposed technique is implemented in the working platform of Mat Lab environment with a greater system specification. The validations and results are discussed in the following sections.

\subsection{Efficiency of Parabolic Trough Collector}

The thermal analysis can be undergone by measuring the thermal performance by evaluating the temperature variation of fluid in the receiver. The evaluation of the thermal efficiency of the parabolic trough collector based on the heat energy by working fluid is derived from the following equation. The performance of the parabolic trough collector is determined by obtaining values of the instantaneous thermal efficiency and the system efficiency for different values of incident radiation, ambient temperature, and inlet water temperature, and the useful energy, $Q_{u}$, is calculated from the measurement of the inlet and outlet fluid temperature and the mass flow rate ' $m$ ' as follows.

$$
Q_{u}=m C_{p}\left(T_{o}-T_{i}\right)
$$

The optical efficiency of the concentrator was expressed as

$$
\eta_{\text {opt }}=\rho_{m} \cdot \gamma \cdot \alpha \cdot K_{c a m}
$$

where $\rho_{m}$ is the reflectance factor of the mirror; $K_{\text {cam }}$ is the angle of incidence correction factor modified; $\alpha$ is the absorption coefficient of the absorber tubes; and $\gamma$ is the intercept factor. The heat flow is transmitted to the fluid such that the power gained to the collector $q u(W)$ is given by the following relationship.

$$
q_{u}=h_{F} \cdot A_{A, \text { int }}\left(T_{A}-T_{F}\right)
$$

where $A_{A \text {,int }}$ is the internal surface of the absorber tube $\left(\mathrm{m}^{2}\right) ; T_{A}$ is the absorber tube temperature $\left({ }^{\circ} \mathrm{C}\right) ; T_{F}$ is the fluid's temperature $\left({ }^{\circ} \mathrm{C}\right) . h_{F}$ is the coefficient of heat exchange by convection; it is often given by the following relation:

$$
h_{F}=\frac{N_{u} \times K_{F}}{D_{A, \text { int }}}
$$


where $K_{F}$ is the thermal conductivity of the fluid, and $N_{u}$ is the Nusselt number. Gnielinski provides a linear interpolation in the transition region between the laminar and turbulent flow; in this case, the useful transfer coefficient depends on two dimensionless Reynolds and Prandtl numbers.

$$
N u=\frac{(f / 8)\left(\operatorname{Re}_{F}-1000\right) \operatorname{Pr}_{F}}{1+12.7 \sqrt{f / 8}\left(\operatorname{Pr}_{F}^{2 / 3}-1\right)}
$$

The coefficient of friction $(f)$ is calculated from the relation of Petukhov:

$$
f=\frac{1}{\left(0.079 \operatorname{Ln}\left(\operatorname{Re}_{F}\right)-1.64\right)^{2}}
$$

with $\left(\operatorname{Re}_{F}\right)$ presenting the Reynolds number, which is expressed by the following relation:

$$
\operatorname{Re}_{F}=\frac{4 \times \rho_{F} \times Q_{v}}{\pi \times D_{A, \text { int }} \times \mu_{F}}
$$

with $\mu_{F}$ being the dynamic viscosity of the fluid $(\mathrm{Kg} / \mathrm{ms}), \rho_{F}$ the fluid density $\left(\mathrm{Kg} / \mathrm{m}^{3}\right), A_{c}$ the collector aperture area $\left(\mathrm{m}^{2}\right)$, and $Q_{v}$ the volume flow rate $\left(\mathrm{m}^{3} / \mathrm{s}\right)$.

The Prandtl number (Pr) is given by

$$
\operatorname{Pr}_{F}=\frac{v_{F}}{\alpha_{F}}
$$

with $\left(v_{F}\right)$ being the kinematic viscosity $\left(\mathrm{m}^{2} / \mathrm{s}\right)$ and $\left(\alpha_{F}\right)$ the fluid thermal diffusivity $\left(\mathrm{m}^{2} / \mathrm{s}\right)$.

The convective heat transfer coefficient $h_{w}$ between the receiver and ambient air due to wind can be calculated as

$$
h_{w}=\frac{N u \cdot K_{a i r}}{D_{o}}
$$

From equation (23), the Nusselt number can be specified as

$$
N u=\frac{h_{w} \cdot D_{0}}{K_{a i r}}
$$

The Nusselt number indicates the enhancement of heat transfer through a fluid layer because of convection concerning conduction over a similar fluid layer.

The radiation heat transfer coefficient $h_{r}$ between receiver surfaces to ambient temperature can be calculated from the equation

$$
h_{r}=\sigma \varepsilon\left(T_{r}+T_{a}\right)\left(T_{t}^{2}+T_{a}^{2}\right)
$$

The overall heat loss coefficient may be determined using the following relation:

$$
q L=h_{w}+h_{r}
$$

The thermal efficiency of a collector $\eta$ can be represented as the optical efficiency, $\eta_{o}$, minus an efficiency penalty term, $\eta^{\prime}$, representing the loss coefficient.

$$
\eta=\eta_{o}-\eta^{\prime}
$$




$$
\eta^{\prime}=\frac{n q L}{I A_{c}}
$$

The total heat loss ' $q L$ ' is from an individual receiver, and $n$ represents the number of receivers limited in a collector module, $I$ is the direct normal solar radiation, and $A_{c}$ is the aperture area of the collector. Parabolic trough collector efficiency depends on the ambient temperatures and can be evaluated by the equation below. The thermal efficiency of a parabolic trough collector is measured using the pyrheliometer. The evaluation is undergone by measuring the collector efficiency at ambient temperature, and it measures separately the heat loss of the receiver in an indoor test lab. The test concern of the factors such as mass flow rate, specific heat, and fluid temperature rises. Thus, the optical efficiency can be evaluated from the following equation:

$$
\eta_{o}=\frac{m C_{p}\left(T_{\text {out }}-T_{\text {in }}\right)}{I A_{c}}
$$

where $m$ is the mass flow rate of the fluid, $C_{p}$ is the constant pressure specific heat, $\left(T_{\text {out }}-T_{\text {in }}\right)$ is the temperature rise, $I$ is the direct normal insolation in the plane of the collector, and $A_{c}$ is the collector aperture area. In the indoor receiver heat loss tests, electric heating is used to bring the receiver to a steady-state temperature. The heat loss is then equal to the electric heat added (Jaramillo et al., 2016).

\subsection{Experimental Data Collection}

Data are gathered from the parabolic trough collectors, and the gathered information is prepared with the above equations. The two groups of data that are observed are real-time data and slow data. The real-time data are estimated and recorded in two-second increments and incorporate date, time, and information including the determined sun angle, the gatherers tracking angles, and sun sensor voltages. The slow data incorporates air temperature, relative humidity, wind speed, and direction, precipitation, and so on. The data are used in the Mat Lab simulation system for the prediction of thermal characteristics. The prediction of the thermal property of PCM based solar thermal collector is analyzed in the Mat Lab with the experimented data, and the test result is plotted in the given tables below.

Table 3. Performance Measures of Collector Efficiency.

\begin{tabular}{|c|c|c|c|c|c|c|c|c|c|}
\hline$m$ & $K_{c a m}$ & $I$ & $Q_{u}$ & $\eta_{\text {opt }}$ & $q u$ & $h_{w}$ & $h_{r}$ & $q L$ & $\eta$ \\
\hline 0.005 & 10 & 500 & 0.178 & 6.011192 & 6713.667 & -437.489 & 0.059176 & -437.43 & 0.272418 \\
\hline 0.033 & 10 & 500 & 1.1748 & 6.011192 & 6713.667 & -437.489 & 0.059176 & -437.43 & 0.272728 \\
\hline 0.166 & 10 & 500 & 5.9096 & 6.011192 & 6713.667 & -437.489 & 0.059176 & -437.43 & 0.274202 \\
\hline 0.005 & 20 & 500 & 0.178 & 12.02238 & 6713.667 & -437.489 & 0.059176 & -437.43 & 0.272418 \\
\hline 0.033 & 20 & 500 & 1.1748 & 12.02238 & 6713.667 & -437.489 & 0.059176 & -437.43 & 0.272728 \\
\hline 0.166 & 20 & 500 & 5.9096 & 12.02238 & 6713.667 & -437.489 & 0.059176 & -437.43 & 0.274202 \\
\hline 0.005 & 40 & 500 & 0.178 & 24.04477 & 6713.667 & -437.489 & 0.059176 & -437.43 & 0.272418 \\
\hline 0.033 & 40 & 500 & 1.1748 & 24.04477 & 6713.667 & -437.489 & 0.059176 & -437.43 & 0.272728 \\
\hline 0.166 & 40 & 500 & 5.9096 & 24.04477 & 6713.667 & -437.489 & 0.059176 & -437.43 & 0.274202 \\
\hline 0.005 & 10 & 800 & 0.178 & 6.011192 & 6713.667 & -437.489 & 0.059176 & -437.43 & 0.170261 \\
\hline 0.033 & 10 & 800 & 1.1748 & 6.011192 & 6713.667 & -437.489 & 0.059176 & -437.43 & 0.170455 \\
\hline
\end{tabular}




\begin{tabular}{|l|l|l|l|l|l|l|l|l|l|}
\hline 0.166 & 10 & 800 & 5.9096 & 6.011192 & 6713.667 & -437.489 & 0.059176 & -437.43 & 0.171376 \\
\hline 0.005 & 20 & 800 & 0.178 & 12.02238 & 6713.667 & -437.489 & 0.059176 & -437.43 & 0.170261 \\
\hline 0.033 & 20 & 800 & 1.1748 & 12.02238 & 6713.667 & -437.489 & 0.059176 & -437.43 & 0.170455 \\
\hline 0.166 & 20 & 800 & 5.9096 & 12.02238 & 6713.667 & -437.489 & 0.059176 & -437.43 & 0.171376 \\
\hline 0.005 & 40 & 800 & 0.178 & 24.04477 & 6713.667 & -437.489 & 0.059176 & -437.43 & 0.170261 \\
\hline 0.033 & 40 & 800 & 1.1748 & 24.04477 & 6713.667 & -437.489 & 0.059176 & -437.43 & 0.170455 \\
\hline 0.166 & 40 & 800 & 5.9096 & 24.04477 & 6713.667 & -437.489 & 0.059176 & -437.43 & 0.171376 \\
\hline 0.005 & 10 & 1000 & 0.178 & 6.011192 & 6713.667 & -437.489 & 0.059176 & -437.43 & 0.136209 \\
\hline 0.033 & 10 & 1000 & 1.1748 & 6.011192 & 6713.667 & -437.489 & 0.059176 & -437.43 & 0.136364 \\
\hline 0.166 & 10 & 1000 & 5.9096 & 6.011192 & 6713.667 & -437.489 & 0.059176 & -437.43 & 0.137101 \\
\hline 0.005 & 20 & 1000 & 0.178 & 12.02238 & 6713.667 & -437.489 & 0.059176 & -437.43 & 0.136209 \\
\hline 0.033 & 20 & 1000 & 1.1748 & 12.02238 & 6713.667 & -437.489 & 0.059176 & -437.43 & 0.136364 \\
\hline 0.166 & 20 & 1000 & 5.9096 & 12.02238 & 6713.667 & -437.489 & 0.059176 & -437.43 & 0.137101 \\
\hline 0.005 & 40 & 1000 & 0.178 & 24.04477 & 6713.667 & -437.489 & 0.059176 & -437.43 & 0.136209 \\
\hline 0.033 & 40 & 1000 & 1.1748 & 24.04477 & 6713.667 & -437.489 & 0.059176 & -437.43 & 0.136364 \\
\hline 0.166 & 40 & 1000 & 5.9096 & 24.04477 & 6713.667 & -437.489 & 0.059176 & -437.43 & 0.137101 \\
\hline
\end{tabular}

In table 3, the efficiency of the solar parabolic trough collector is evaluated numerically with evaluation of different parameters such as mass flow rate, angle of incidence, and solar insolation, respectively. The parameters analyzed at different points such as mass flow rate range from $0.55,0.033$, and 0.166 with an angle of incidence of 10, 20, and 40 and solar insolation of 500, 800, and 1000, respectively.

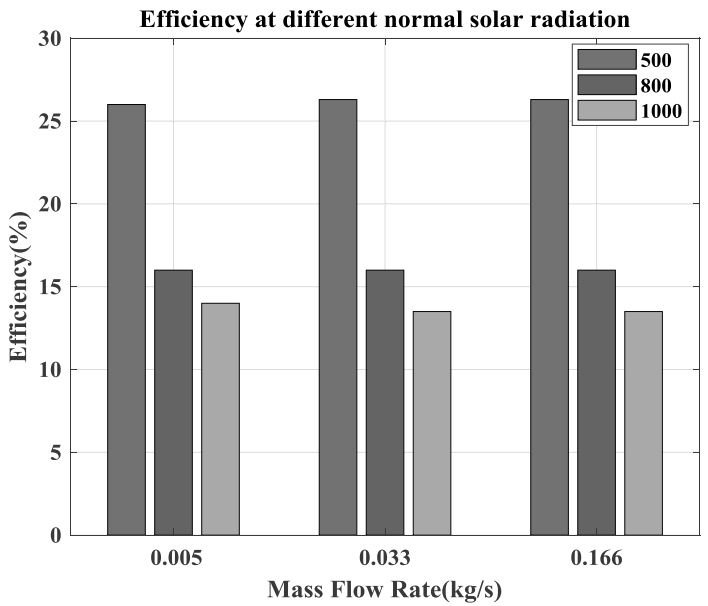

Figure 6. Performance Measures of PCM-Parabolic Trough Collector. 
In figure 6, the efficiency of thermal energy for the proposed PCM composition is evaluated for the different mass flow rate of the collector fluid. At different solar radiations, the thermal efficiency varied for different operating conditions (such as mass flow rate, angle of incidence, and solar insolation). The result indicates that the efficiency of the trough collector is more optimal in terms of thermal energy storage for a definite number of solar intensity and mass flow rates, respectively. From the analyzed results, it is shown that the proposed PCM-parabolic trough collector combination has a higher rate of efficiency than conventionally practiced trough collectors, respectively.

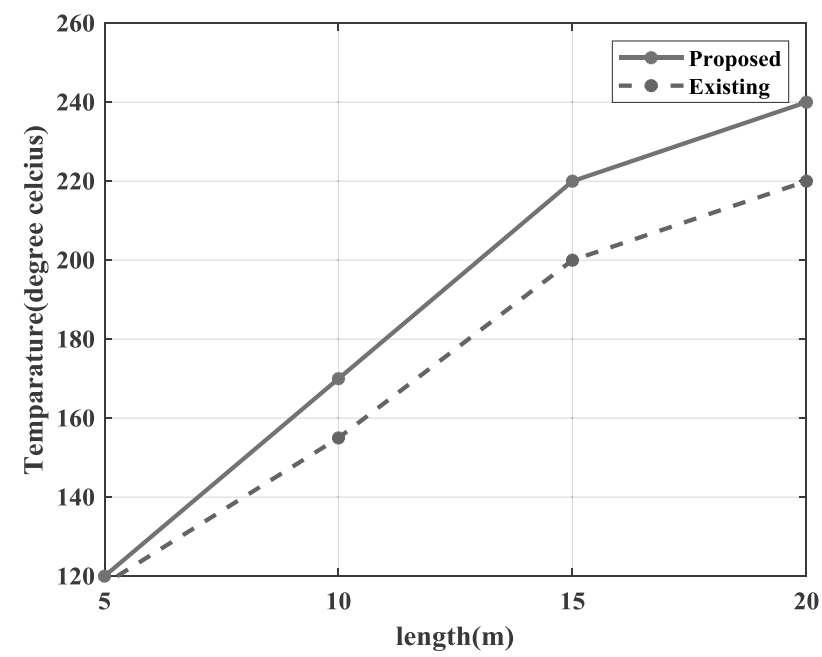

Figure 7. Comparison of Thermal Efficiency.

In figure 7, the temperature efficiency of collector tube length is compared with existing and proposed parabolic trough collector combinations. The evaluation of temperature gain is analyzed for different lengths ranging from 5 to 20 meters, respectively. From the analysis, the temperature rises higher than $245^{\circ} \mathrm{C}$ for 20 -meter length in the proposed composition and lower than $230^{\circ} \mathrm{C}$ for 20 -meter length in the existing composition. Thus, the temperature improvement in the proposed collector combination for obtaining better efficiency in terms of temperature, respectively.

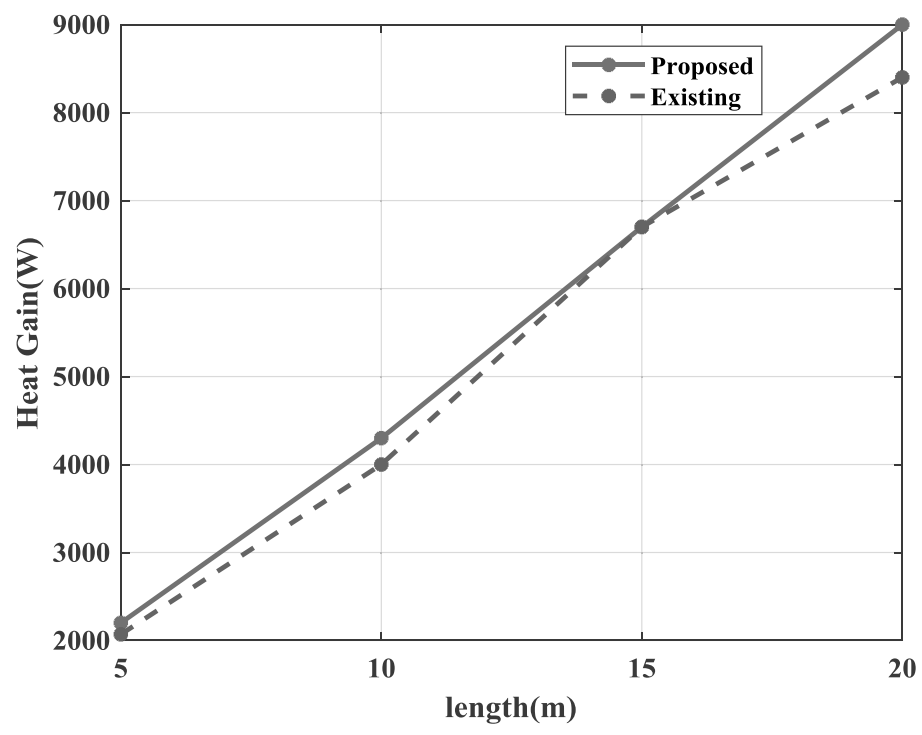

Figure 8. Comparison of Heat Gain in Trough Collector. 
In figure 8, the comparison of heat gain for parabolic trough collector is compared with existing and proposed collector efficiencies. The heat gain is measured for different length ranges of heat transfer fluid. The length measurements range from 5- to 20-meter long, and heat capacity of the fluid is measured in terms of heat gain. The analyzed results prove that the proposed fluid composition has a higher heat capacity of $9000 \mathrm{~W}$, and the existing score lower range is $8300 \mathrm{~W}$, respectively. From the test evaluation, it is concluded that the proposed combination of the fluid medium has higher heat-conducting capacity than existing approaches, respectively.

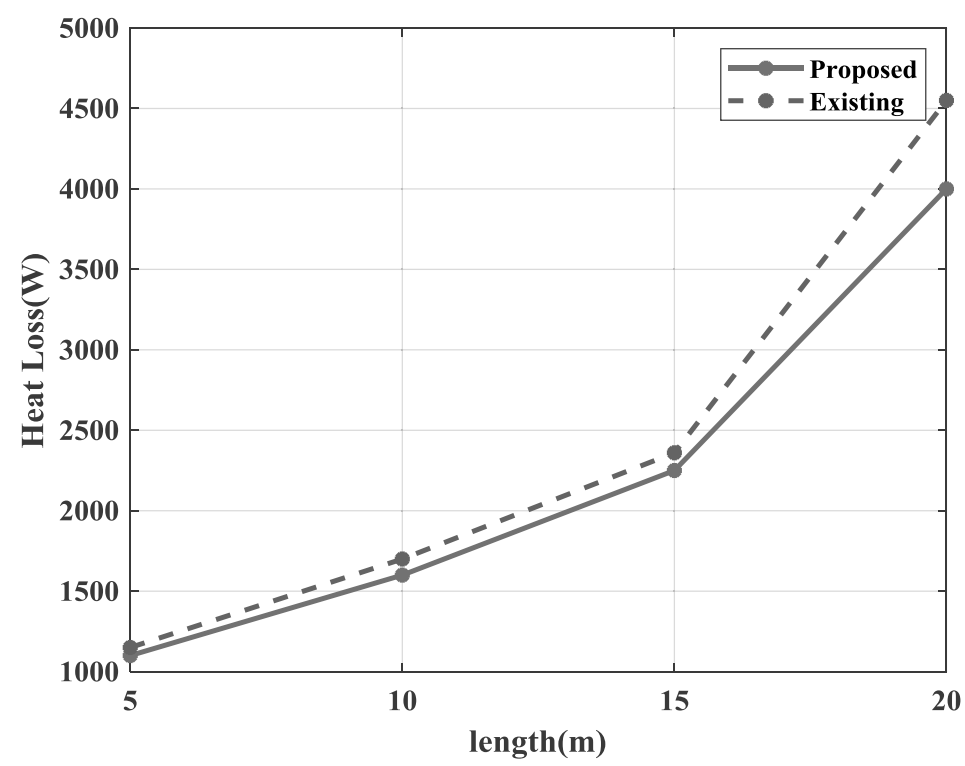

Figure 9. Comparison of Heat Loss in Trough Collector.

In figure 9, the total loss in the parabolic trough collector is compared with the existing and proposed fluid compositional mixtures. The total heat loss during the solar radiation is tested at a different flow rate and solar insolation and evaluated for different length parameters, respectively. The heat loss in the fluid for the proposed combination has a lower range of $4200 \mathrm{~W}$, while the existing score is higher than $4520 \mathrm{~W}$, respectively. The results show that the proposed fluid combination has less heat loss than the existing approach.

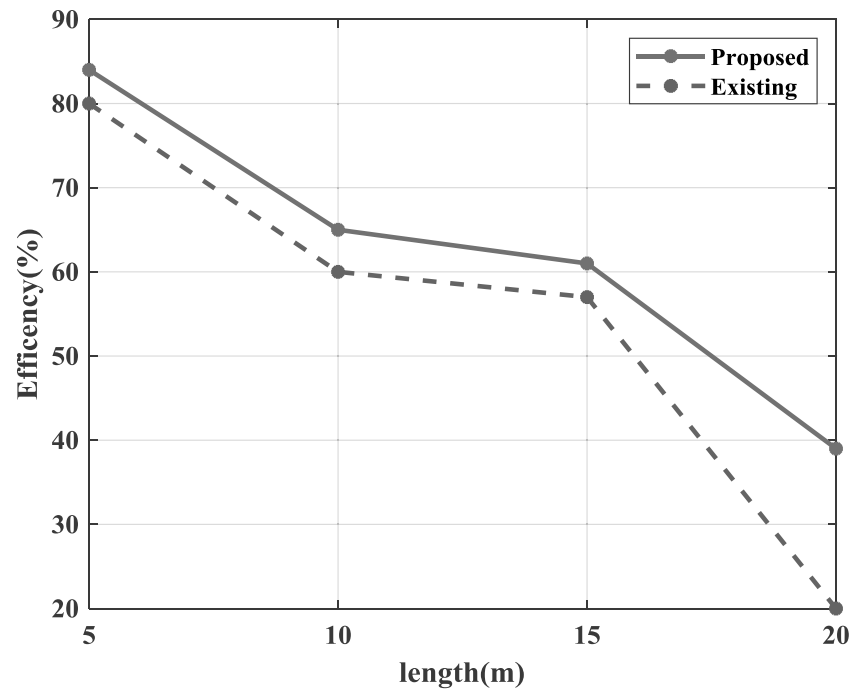

Figure 10. Comparison of Efficiency. 
In figure 10, the efficiency of the collector is analyzed and compared with existing and proposed parabolic trough collectors for better efficiency ratio. The efficiency is measured based on the thermal energy generation for the collector fluid combination. The evaluation is undergone with varying the length of the collector in the range of 5-20 meters. The efficiency of the proposed approach is higher than $85 \%$, and the existing scores are lower than $80 \%$, respectively. From the evaluation, it is shown that the proposed composition has higher efficiency than the conventionally practiced composition.

\subsection{Discussions of Comparison Criteria}

The performances of PTC had been enhanced by using different kinds of substances including nanoparticles, PCMs, methanol, and acetone. In this research work, the performances of PTC are enhanced by means of $\mathrm{MgCl}_{2}$. $6 \mathrm{H}_{2} \mathrm{O}$ composition.

PCM erythritol is used for improving the storage efficiency of the solar collector (Li et al., 2018). The achieved rate of storage efficiency is $40 \%$, and the obtained outlet temperature is $135^{\circ} \mathrm{C}$.

The PCM based photovoltaic thermal collector system is fabricated to enhance the energy storage system, in which the obtained overall efficiency is $60 \%$, and the temperature is $125^{\circ} \mathrm{C}$ (Senthil, R. and Cheralathan, M., 2019).

The efficiency rate and the temperature obtained from our proposed work are $85 \%$ and $250{ }^{\circ} \mathrm{C}$. The comparison of temperature and the energy efficiency rates for the existing PCM based material are given in tables 4 and 5 .

Table 4. Comparison of Solar collector based on Temperature.

\begin{tabular}{|c|c|}
\hline $\begin{array}{c}\text { PCM based solar } \\
\text { collector researches }\end{array}$ & Temperature \\
\hline $\begin{array}{c}\mathrm{MgCl}_{2} .6 \mathrm{H}_{2} \mathrm{O} \text { PCM based } \\
\text { PTC (Proposed) }\end{array}$ & $240^{\circ} \mathrm{C}$ \\
\hline Guerraiche et al., 2020 & $230^{\circ} \mathrm{C}$ \\
\hline Kargar et al., 2018 & $80^{\circ} \mathrm{C}$ \\
\hline Li et al., 2018 & $120^{\circ} \mathrm{C}$ \\
\hline Badiei et al., 2020 & $140^{\circ} \mathrm{C}$ \\
\hline $\begin{array}{c}\text { Senthil, R. and } \\
\text { Cheralathan, M., 2019 }\end{array}$ & $125^{\circ} \mathrm{C}$ \\
\hline Raja et al., 2018 & $60^{\circ} \mathrm{C}$ \\
\hline
\end{tabular}

Table 5. Comparison of Solar collector based on Thermal Efficiency.

\begin{tabular}{|c|c|}
\hline $\begin{array}{c}\text { PCM based solar } \\
\text { collector researches }\end{array}$ & Efficiency \\
\hline $\begin{array}{c}\mathrm{MgCl}_{2} \text {. 6 } \mathrm{H}_{2} \mathrm{O} \text { PCM based } \\
\text { PTC (Proposed) }\end{array}$ & $85 \%$ \\
\hline $\begin{array}{c}\text { Senthil, R. and } \\
\text { Cheralathan, M., 2019 }\end{array}$ & $70 \%$ \\
\hline $\mathrm{Al}$ Imam et al., 2016 & $60 \%$ \\
\hline Sajawal et al., 2019 & $97 \%$ \\
\hline Salari et al., 2020 & $61 \%$ \\
\hline Chopra et al., 2019 & $73 \%$ \\
\hline
\end{tabular}




\section{RESEARCH CONCLUSION}

Expanding energy demands and decreasing fuel resources and environmental problems have assisted the examination of individual, sustainable energy sources. Renewable energy source systems receive few qualities. For instance, they are available because there is a constant supply of resources. Furthermore, renewable energy sources are spotless and useful for the environment. Energy researchers around the globe are focused on finding and creating renewable power source system to reduce relationship on fuel products. Solar energy is a standout energy amongst the essential wellsprings of renewable energy sources currently available. This paper elaborates the utilization of solar energy for the generation of thermal energy and storage system by proposing phase change materials as the collector fluid for the thermal energy storage system. The proposed $\mathrm{MgCl}_{2} .6 \mathrm{H}_{2} \mathrm{O}$ composition is more optimal for developing thermal energy in the parabolic trough collector system. The evaluation is carried out in different phases of operation by utilizing the parameters such as mass flow rate, solar intensity, and incidence angle. The evaluation criteria are undergone by numerically modelling the thermal efficiency of the system, and an optimization algorithm is utilized to find out the optimal parameter selection for thermal efficiency of the system. The proposed methodologies are mathematically modelled and experimented in the running platform of Mat Lab and executed in terms of thermal efficiency of the PCM based parabolic trough collector. The proposed framework has a lower range of heat loss in the fluid as $4200 \mathrm{~W}$ and the current score has a higher range of $4520 \mathrm{~W}$. The efficiency of the proposed methodology is distinguished as $85 \%$, and the current framework has $80 \%$. From the research analysis, it is concluded that the proposed PCM composition in solar collectors gives more efficiency than conventional fluid composition in terms of rated thermal efficiency and is more optimal for generating thermal energy in solar parabolic trough collectors. In future, this experimental work can be extended by choosing the organic phase change materials like paraffin, carbohydrates, and lipid determined substances rather than $\mathrm{MgCl}_{2} .6 \mathrm{H}_{2} \mathrm{O}$.

\section{REFERENCES}

Aghajani, A., Kazemzadeh, R \& Ebrahimi, A. 2016. A novel hybrid approach for predicting wind farm power production based on wavelet transform, hybrid neural networks and imperialist competitive algorithm, Energy Conversion and Management, 121(1): 232-240.

Al Dossary, M.A \& Nasrabadi, H. 2016. Well placement optimization using imperialist competitive algorithm, Journal of Petroleum Science and Engineering, 147(1): 237-248.

Al Imam, M.F.I., Beg, R.A., Rahman, M.S. and Khan, M.Z.H. 2016. Performance of PVT solar collector with compound parabolic concentrator and phase change materials. Energy and Buildings, 113: 139-144.

Almsater, S., Saman, W \& Bruno, F. 2016. Performance enhancement of high temperature latent heat thermal storage systems using heat pipes with and without fins for concentrating solar thermal power plants, Renewable Energy, 89(1): 36-50.

Arunkumar, T \& Kabeel, A.E. 2017. Effect of phase change material on concentric circular tubular solar still-Integration meets enhancement. Desalination, 414: 46-50.

Badiei, Z., Eslami, M. and Jafarpur, K. 2020. Performance improvements in solar flat plate collectors by integrating with phase change materials and fins: A CFD modeling. Energy, 192: 116719.

Bellos, E \&Tzivanidis, C. 2019. Thermal efficiency enhancement of nanofluid-based parabolic trough collectors. Journal of Thermal Analysis and Calorimetry, 135(1): 597-608.

Bellos, E \& Tzivanidis, C. 2019. Thermal efficiency enhancement of nanofluid-based parabolic trough collectors.' Journal of Thermal Analysis and Calorimetry, 135(1): 597-608.

Bellos, E., et al. 2016. Thermal enhancement of solar parabolic trough collectors by using nano fluids and converging-diverging absorber tube, Renewable Energy, 94(1): 213-222.

Bijarniya, P.J., Sudhakar, K \& Baredar, P. 2016. Concentrated solar power technology in India: A review, Renewable and Sustainable Energy Reviews, 63(1): 593-603.

Chandra, P.Y., et al. 2017. Numerical optimization and convective thermal loss analysis of improved solar parabolic trough collector receiver system with one sided thermal insulation. Solar Energy 148: 36-48. 
Chopra, K., Tyagi, V.V., Pathak, A.K., Pandey, A.K. \& Sari, A. 2019. Experimental performance evaluation of a novel designed phase change material integrated manifold heat pipe evacuated tube solar collector system. Energy Conversion and Management, 198: 111896.

Da Cunha, P.J \& Eames, P. 2016. Thermal energy storage for low and medium temperature applications using phase change materials-a review, Applied Energy, 177(1): 227-238.

Deng, Y., et al., 2016. Thermal conductivity enhancement of polyethylene glycol/expanded vermiculite shape-stabilized composite phase change materials with silver nanowire for thermal energy storage, Chemical Engineering Journal, 295(1): 427-435.

Ghasemi, E.S \& Ranjbar, A.A. 2017. Numerical thermal study on effect of porous rings on performance of solar parabolic trough collector. Applied Thermal Engineering, 118: 807-816.

Guerraiche, D., Bougriou, C., Guerraiche, K., Valenzuela, L. \& Driss, Z. 2020 Feb 1. Experimental and numerical study of a solar collector using phase change material as heat storage. Journal of Energy Storage., 27: 101133.

Heng, Y.S., et al. 2019. Transient thermal prediction methodology for parabolic trough solar collector tube using artificial neural network. Renewable energy, 131: 168-179.

Jaramillo, O.A., et al. 2016. Parabolic trough solar collector for low enthalpy processes: An analysis of the efficiency enhancement by using twisted tape inserts, Renewable energy, 93(1): 125-141.

Kapsalis, V \& Karamanis, D. 2016. Solar thermal energy storage and heat pumps with phase change materials, Applied Thermal Engineering, 99: 1212-1224.

Kargar, M.R., Baniasadi, E. \& Mosharaf-Dehkordi, M. 2018. Numerical analysis of a new thermal energy storage system using phase change materials for direct steam parabolic trough solar power plants. Solar Energy, 170: 594-605.

Kargar, R.M., Baniasadi, E \& Mosharaf-Dehkordi, M. 2018. Numerical analysis of a new thermal energy storage system using phase change materials for direct steam parabolic trough solar power plants. Solar Energy, 170: 594-605.

Li, B., Zhai, X. \& Cheng, X. 2018. Experimental and numerical investigation of a solar collector/storage system with composite phase change materials. Solar Energy, 164: 65-76.

Li, Z., Rahman, S.M., Vega, R. \& Dong, B. 2016. A hierarchical approach using machine learning methods in solar photovoltaic energy production forecasting, Energies, 9(1): 55.

Ling, Z., et al. 2017. $\mathrm{MgCl} 2 \cdot 6 \mathrm{H} 2 \mathrm{O}-\mathrm{Mg}$ (NO3) 2. 6H2O eutectic/SiO2 composite phase change material with improved thermal reliability and enhanced thermal conductivity. Solar Energy Materials and Solar Cells, 172: 195-201.

Liu, L., Su, D., Tang, Y. \& Fang, G. 2016. Thermal conductivity enhancement of phase change materials for thermal energy storage: A review, Renewable and Sustainable Energy Reviews, 62(1): 305-317.

Liu, M., Tay, N.S., Bell, S., Belusko, M., Jacob, R., Will, G. \& Bruno, F. 2016. Review on concentrating solar power plants and new developments in high temperature thermal energy storage technologies, Renewable and Sustainable Energy Reviews, 53(1): $1411-1432$.

Mamani, V., Gutierrez, A \& Ushak, S. 2018. Development of low-cost inorganic salt hydrate as a thermochemical energy storage material. Solar Energy Materials and Solar Cells, 176: 346-356.

Mao, Q. 2016. Recent developments in geometrical configurations of thermal energy storage for concentrating solar power plant, Renewable and Sustainable Energy Reviews, 59(1): 320-327.

Menbari, A., Alemrajabi, A.A \& Rezaei, A. 2017. Experimental investigation of thermal performance for direct absorption solar parabolic trough collector (DASPTC) based on binary nanofluids. Experimental Thermal and Fluid Science, 80: 218-227.

Norouzi, A.M., Siavashi, M \& Oskouei, M.K. 2020. Efficiency enhancement of the parabolic trough solar collector using the rotating absorber tube and nanoparticles. Renewable Energy, 145: 569-584.

Qiu, Y., et al. 2017. Thermal performance analysis of a parabolic trough solar collector using supercritical CO2 as heat transfer fluid under non-uniform solar flux. Applied Thermal Engineering, 115: 1255-1265.

Raja, S., Prakash, S., Gokulnath, R., Krishnamoorthy, A. \& Lillymercy, J. 2018. PCM based thermal energy storage system integrated with solar parabolic trough collector. Journal of Engineering Science and Technology, 13: 40-51.

Richareon, V., Peerapat \& MacGill, I.F. 2016. Valuing large-scale solar photovoltaics in future electricity generation portfolios 
and its implications for energy and climate policies, IET Renewable Power Generation, 10(1): 79-87.

Sajawal, M., Rehman, T.U., Ali, H.M., Sajjad, U., Raza, A. \& Bhatti, M.S. 2019. Experimental thermal performance analysis of finned tube-phase change material based double pass solar air heater. Case Studies in Thermal Engineering, 15: 100543.

Salari, A., Kazemian, A., Ma, T., Hakkaki-Fard, A. \& Peng, J. 2020. Nanofluid based photovoltaic thermal systems integrated with phase change materials: Numerical simulation and thermodynamic analysis. Energy Conversion and Management, 205: 112384 .

Sani, E., Papi, N., Mercatelli, L. \& Żyła, G. 2018. Graphite/diamond ethylene glycol nanofluids for solar energy applications. Renewable energy, 126: 692-698.

Senthil, R. \& Cheralathan, M. 2019. Enhancement of the thermal energy storage capacity of a parabolic dish concentrated solar receiver using phase change materials. Journal of Energy Storage, 25: 100841.

Wang, T., et al., 2016. Microencapsulation of phase change materials with binary cores and calcium carbonate shell for thermal energy storage, Applied energy, 171(1): 113-119.

Wang, Y., Xu, J., Liu, Q., Chen, Y. \& Liu, H. 2016. Performance analysis of a parabolic trough solar collector using Al2O3/ synthetic oil nanofluid. Applied Thermal Engineering, 107: 469-478.

Widyolar, B.K., et al. 2017. Design, simulation and experimental characterization of a novel parabolic trough hybrid solar photovoltaic/thermal (PV/T) collector, Renewable energy, 101(1): 1379-1389.

Zhang, P., Xiao, X \& Ma, Z.W. 2016. A review of the composite phase change materials: Fabrication, characterization, mathematical modeling and application to performance enhancement, Applied Energy, 165(1): 472-510. 